\title{
Puertas abiertas y buenos vigilantes
}

\author{
Joan Navarro ${ }^{1}$ \\ Sociólogo, socio y vicepresidente de Llorente \& Cuenca \\ jnavarro@1lorenteycuenca.com
}

DOI: http://dx.doi.org/10.20318/eunomia.2016.3295

\section{Una mala regulación y un peor desempeño}

¿Es comprensible que un alto cargo del Ministerio de Defensa, con competencia directa en la regulación y compra de armamento, pase, 14 días después de cesar en su responsabilidad, a ser directivo de una empresa que, durante su mandato, recibió 1.200 millones de euros de su Ministerio? ¿Es comprensible que, dentro de los dos años de incompatibilidad que la ley establece, un consejero de un órgano de regulación acabe en una filial o fundación de una empresa sobre la que ese organismo había emitido resoluciones? No, no es comprensible, puede ser legal, pero no es comprensible. Precisamente para evitar estos casos (y, al parecer, bastantes más) el Gobierno estableció en 2006 una ley de incompatibilidades de sus Altos Cargos y creó una Oficina de Conflictos de Intereses para dirimirlos.

La prevaricación, el cohecho o el tráfico de influencias son delitos penados en el Código Penal. Pero la dificultad de identificar si un funcionario o alto cargo ha tomado una decisión motivado por una recompensa futura, generando de este modo un perjuicio a la Administración, determinó que se adoptara una legislación para proteger el interés general mediante desincentivos a un hipotético intercambio de favores, obligando a hacer públicos los datos de actividad, a registrar los datos patrimoniales, obligando a inhibirse en las decisiones que puedan afectar a intereses pasados o presentes, directos $o$ de familiares y otras personas relacionadas, y estableciendo periodos en los que no se puede prestar ningún tipo de servicio o actividad a empresas o intereses sobre los que se ha actuado desde la responsabilidad pública. Para muchos directivos públicos, estos requisitos han supuesto auténticos esfuerzos de reciclaje profesional; para otros, está a la vista, no.

Casos como los comentados pueden ser legales porque la ley se pueda sortear, es decir: que esté mal hecha, pero también porque incurran causas que

\footnotetext{
${ }^{1}$ Fue Director del Gabinete del Ministro de Administraciones Publicas (2004-2007) durante el periodo en que se aprobó en "Código de Buen Gobierno de los miembros del Gobierno y de los Altos Cargos de la AGE y la ley 5/2006 de regulación de los conflictos de intereses de los miembros del Gobierno y de los Altos Cargos de la AGE.
} 
hagan que aplicar una incompatibilidad no tenga sentido; por ejemplo, porque el alto cargo nunca tuvo participación directa en las decisiones, o porque precisamente estas eran sus empresas de origen y nunca intervino en una decisión que la pudiera beneficiar. Lo malo es que nunca lo sabremos, no hay obligación de dar cuenta de qué criterios determinaron que no se aplique la incompatibilidad y, por lo tanto, no sabremos con qué criterios se ha autorizado la actividad privada. La falta de transparencia, y sobre todo la falta de independencia de esta oficina que, dependiendo del ejecutivo, tiene como misión juzgarse a sí misma, no ayuda a la generación de confianza, sino todo lo contrario.

Yo participé en la elaboración de la ley 5/2006 de regulación de los conflictos de intereses de los miembros del Gobierno y de los Altos Cargos de la AGE, modificada por el PP en 2015. La primera ley fue insuficiente; la segunda, mejoraba algunas cosas, empeoraba otras y no resolvió ninguno de los problemas de la anterior. En un contexto donde la desconfianza de los ciudadanos respecto de sus poderes públicos ha pasado de la duda sobre si tenemos una buena administración a la certeza de no tenerla, los apaños administrativos no solo no resuelven nada, sino que ayudan a empeorar la percepción social sobre el funcionamiento de lo público. Y la percepción de nuestros ciudadanos, hoy, es que los políticos se protegen entre ellos y se relacionan ilegítimamente con los poderes económicos, una percepción que, pese a casos como los mencionados, es injusta con nuestra Administración, es injusta con la gran mayoría de nuestros políticos y de nuestras empresas $\mathrm{y}$, además, supone un serio riesgo para la legitimidad de nuestra democracia.

\section{Un lamentable debate político: crear desconfianza nos debilita.}

Una mala ley y un peor desempeño, así como la más absoluta falta de tacto, de transparencia y de voluntad de rendir cuentas, forman parte del peor servicio que la Administración, los propios altos cargos y los miembros del Gobierno pueden hacerse a sí mismos y a la democracia, pues no hay nada más corrosivo para la democracia que la falta de confianza; bueno, sí, la absoluta convicción de que nos engañan.

No puedo estar más de acuerdo con los que afirman que, pese a los constantes casos de corrupción que minan nuestra convivencia, estos se conocen porque en nuestro país las fuerzas y cuerpos y de seguridad funcionan, la fiscalía muestra (suficiente) independencia y la justicia es lenta, pero actúa. Tenemos una Administración que, pese a las convulsiones que estamos viviendo en nuestro sistema político, atiende razonablemente bien los servicios públicos, así como un cuerpo político sobre el que no hay más sospechas de corrupción que en los países de nuestro entorno. Pero ni atender razonablemente bien los servicios públicos ni ser igual de corruptos que los vecinos debieran ser nuestros objetivos. La ley es mala y las prácticas peores; y lo peor de las malas prácticas, por muy aislados que sean los casos, es que son la gasolina que alimenta la demagogia y el populismo.

"Prohibiremos las puertas giratorias" resume el grito de indignación que casos incomprensibles (y otros muchos comprensibles, pero igualmente utilizables) arranca los aplausos en cualquier mitin o nutre titulares de periódico. Tras la convicción de que "todos los políticos son iguales", qué menos que evitar que estos "nos sigan robando" tras abandonar el cargo. Ser político se está convirtiendo en una actividad de riesgo, desprestigiada, mal pagada, con una dura carrera de entrada y un futuro incierto. Pero no conocemos otra forma mejor de gestionar los asuntos públicos que implicándonos en ellos. No queremos políticos profesionales, pero queremos que resuelvan los más intrincados problemas, precisamente aquellos 
que no tienen una solución científica aceptada y sobre los que la verdad es siempre más que opinable. El trabajo de los políticos requiere del más delicado arte del consenso. Aspiran a que su decisión, puesto que raramente será ni cierta ni verdadera, al menos sea compartida. Minar la confianza en los políticos y en la Administración hace imposible ese espacio compartido, lo que va bien a demagogos y chamanes, y a lo que ayuda la masiva presencia de exministros en consejos de empresas reguladas o que expresidentes del gobierno trabajen para intereses extranjeros.

Creo firmemente que necesitamos puertas abiertas entre lo público y lo privado. Necesitamos parlamentarios y altos cargos que hayan desarrollado carreras brillantes en el sector privado, lo que sin duda aumentaría la eficacia de lo público y la comprensión de la economía y la empresa por parte de sus responsables. Necesitamos directivos privados que hayan tenido experiencia pública, serian más realistas sobre los límites de lo público y entenderían mejor su misión en defensa del interés general. Y para esto necesitamos que el ejercicio público esté sometido a los máximos controles, pero también al máximo reconocimiento. ¿Qué podríamos esperar de un Consejo de Ministros donde todos sus miembros fueran funcionarios de los altos cuerpos del Estado? Pues lo mismo que esperaríamos si sus miembros solo hubieran tenido carreras políticas: incapacidad para entender la complejidad de España.

\section{Un poco de polémica, pero muy cordial.}

También creo firmemente en la profesionalización de la política. Como decía, su complejidad requiere oficio, arte y experiencia, algo que debe ser perfectamente complementario a la pasión e intensidad con la que debemos afrontar los retos de nuestra sociedad. Pero, ¿qué profesional lo es, en una sociedad postindustrial, si desempeña su función siempre en el mismo puesto? Algo que, por cierto, es de aplicación también a los funcionarios. Por tanto, pedir profesionalización en lo público y exigir que los altos cargos sirvan en el mercado, y que los directivos privados tengan experiencia de servicio público, no es contradictorio, sino más bien una posición racional. Lo público y la función política, la gestión de la Administración y la representación institucional, que no es lo mismo pero sirve al mismo ciudadano, deben estar sometidos a criterios de eficacia y de confianza, imposibles de aplicar si obligamos a ciudadanos y directivos privados, por una parte, y a políticos y funcionarios, por otra, a transitar siempre en orillas separadas.

Se pregunta mi querida Elisa, en su interesante reflexión en este mismo espacio, en relación al fenómeno de las puertas giratorias: "¿aumenta el talento disponible en el sector público y en el privado, o más bien es una manera de capturar al regulador o de conseguir una mayor cercanía con el Poder o de ejercer el lobby en sombra?" Y su respuesta, "en un estado de fuertes tintes clientelares", nos habla de "pandillas de fieles" funcionarios de partidos "que saltan de un cargo público a otro" con más que sobradas dudas sobre su capacitación. ¿Cómo negar la evidencia, precisamente en el país que inventó el "turnismo"?.

Pero la desconfianza ante la evidencia de que las cosas funcionan mal no es la respuesta. Hay "fontaneros de partido" tanto o más preparados que altos funcionarios del Estado, pues la política, esa profesión de riesgo, es también una envidiable actividad que, pese a sus miserias, conecta con lo mejor, no solo lo peor, del ser humano. Servir a tu comunidad, la satisfacción de ver cómo lo que ayer eran problemas serios hoy son recuerdos y saber que en algo has contribuido, es algo cuya satisfacción no supera ningún éxito en el sector privado. La respuesta no es cerrar la puerta de la Administración ante la voluntad de colonización de los partidos. 
La respuesta es recolonizar los partidos por los ciudadanos. Reprofesionalizar la Administración no pasa por impedir que nuestros altos funcionarios trabajen luego, o hayan trabajado antes, en el sector privado. La respuesta es exigir que lo hagan en unas condiciones en que lo público gane más, que lo privado. Un político profesional no puede ser una persona condenada a estar toda su vida luchando por cargos públicos sucesivos, porque el desprestigio de lo público impida que el sector privado valore sus habilidades y conocimientos. De la misma forma que un directivo, profesional o empleado del sector privado será mejor profesional si ha tenido ocasión de conocer la complejidad de lo público.

\section{¿Cómo mejoramos esto?.} antipolítica".

"¿Hay algo peor que la mala política? Sí, su ausencia, la mentalidad

"Estamos haciendo un diagnóstico equivocado de la situación, como si el origen de nuestros males fuera el poder de la política y no su debilidad". No me canso de citar a Innerarity en su obra: "Política en tiempos de indignación".

Necesitamos puertas, puentes y... buenos vigilantes. La desconfianza ante el vigilante no puede llevarnos a dinamitar los puentes. "Es una obligación cívica de primera magnitud que entendamos mejor la política, porque sólo así podemos juzgarla con toda la severidad que se merece"; otra vez Innerarity.

Apuesto por profesionalizar la política, entendiendo profesionalización como lo contrario a estancamiento. También abogo por abrir las puertas entre lo público y lo privado, en beneficio de la sociedad, no del cargo público; por tanto, bajo un severo control. Mi última provocación será defender que no necesitamos una ley que persiga el abuso, sino que necesitamos una ley que busque restablecer la confianza de los ciudadanos respecto de sus cargos públicos. Abundaré: no dudo que tanto el PSOE, en 2006, como el PP, en 2015, pretendieran con sus respectivas iniciativas legislativas desincentivar favores "en diferido"; estoy seguro, además, de que la regulación ha logrado desincentivar comportamientos deshonestos, pero la falta de transparencia en las resoluciones, la falta de independencia del organismo respecto de los cargos analizados, y el limitado ámbito de su actuación (solo afecta a altos cargos de la AGE), han logrado que, incluso en aquellos casos en que la actividad privada se produce tras muchos años de separación de lo público, siempre exista la sospecha.

Necesitamos un comportamiento ejemplarizante, no solo eficiente. Necesitamos saber que nuestros cargos públicos son los primeros que persiguen, como principales perjudicados, el comportamiento deshonesto. "Políticos que controlan a políticos", en acertada expresión del profesor Gómez-Yáñez. Necesitamos una Oficina de Conflictos de Intereses, que responda ante el Parlamento, con un presidente de reconocido prestigio (menos influenciable y removible que un alto funcionario) a quien encarguemos la misión de eliminar sospechas, no solo de evacuar expedientes.

Ayudaría imitar los mejores mecanismos relativos a las denuncias, por lo que esta oficina debe contar con recursos y capacidad de inspección, y también con capacidad de actuar contra quien levanta sospechas infundadas o difama.

Los conflictos de intereses deben resolverse en función del "cursus honorem", revisando los periodos de incompatibilidad, incluso incorporando exclusiones vitalicias en algunos casos, como claramente requiere la actividad de 
los expresidentes y algunos ministros, con las correspondientes compensaciones, plenamente al alcance de una sociedad como la española.

Necesitamos ampliar el ámbito de actuación de la Oficina de control de incompatibilidades y conflictos de intereses a quienes tienen capacidad de tomar decisiones públicas relevantes: consejeros independientes en el sector público, altos funcionarios (en especial la inspección, la abogacía del Estado o los comisarios de policía) parlamentarios (como reclama el informe GRECO del Consejo de Europa) y ampliar estas medidas a jueces, fiscales, las administraciones autonómicas y algunos municipios (todo ello, con las debidas cautelas y límites).

La Oficina debería contar con un código ético y el asesoramiento de expertos, y sobre todo con una audaz política de transparencia, aunque proteja cuantos datos de carácter privado sean necesarios. No se trata solo de ser eficaz 0 , mejor dicho, solo es posible ser eficaz en una sociedad desconfiada cuando se rinden cuentas y se presta atención a las exigencias ciudadanas. Solo así se achica el espacio de la duda y la demagogia. 